\title{
Speaking the gendered body: The performative construction of commercial femininities and masculinities via body-part vocabulary
}

\author{
H E I K O M O T S C H E N B A C H E R \\ Linguistics Department, Institute for English and American Studies (IEAS) \\ Goethe University \\ Grüneburgplatz, 1 \\ 60629 Frankfurt am Main, Germany \\ Motschenbacher@em.uni-frankfurt.de; www.quinguistics.de
}

A B S T R A C T

This study illustrates how body-part vocabulary can contribute to linguistic gender construction. As a starting point, gendering mechanisms pertinent to body-part terms are delineated. On a theoretical plane, the study is indebted to poststructuralism and the notion of performativity in identity construction. Gender performativity via body-part vocabulary is explored by quantitatively and qualitatively analyzing material from a corpus of 2,000 advertisements from the two magazines, Cosmopolitan and Men's Health, yielding evidence on how two specific commercial versions of femininity and masculinity are discursively constructed. The findings are highly stereotypical and therefore bear witness to body-part lexemes as traces of dominant gender discourses whose gender indexicality can be strategically exploited. The concluding discussion advances a theorization of linguistic identity construction in line with performativity, which departs from more traditional variationist approaches that see identity as a pre-discursive fact. (Language and gender, body, advertising discourse, body-part vocabulary, poststructuralism, performativity)

I N T R O D U C T I O N

The body has become a central subject in gender studies. Linguistic discussions of the body and its relation to gender, by contrast, are relatively rare. This might be due to the widely held view that the body speaks for itself or has its own kind of language ("body language"), which is different from spoken and written language. Much of contemporary gender research is influenced by poststructuralism. Concomitant approaches to gender elucidate how the body and language are much more closely related than one would think at first. Postmodernist thinkers such as Butler (1990, 1993, 2004) see the gendered body as a discursive construction, in the sense that existing bodies could be more adequately understood as a continuum 
than as a clear-cut binarism of female versus male body. On a linguistic plane, seeing female and male personal nouns such as woman and man as instances of genderbinary body construction deals with the body only on a relatively abstract level. This article will discuss how the body is also discursively gendered when it is not yet personalized, and therefore is more an aggregation of individual body parts.

Gender research, especially in Germany, has come up with a theorization of the body as the interface of social and personal experiences: (i) the body as seen from the external perspective, as an object to be spoken about (Germ. Körper), and (ii) the body as felt from the internal perspective, that is, subjective body experience (Germ. Leib) (see e.g. Stahr 2000:98f). Both facets need not necessarily depend on each other. A person may be judged to be a man from the point of view of an outside observer (Körper), but may nevertheless personally feel like a woman (Leib). The latter concept was deemed necessary for the continuation of political activism in the name of women, thereby eschewing the fallacy that feminism can work only if there is a fixed essence of what it means to be a woman. It is a consequence of the belief that the deconstructed gendered body can no longer serve as the foundation on which to build an identity category. The main part of the present study will primarily refer to the body from the outside perspective (Körper), but links with the inside perspective (Leib) are anything but absent. The analysis will address advertising discourse; it has been claimed that commercial body images as mediated by advertising are one of the reasons why eating disorders and pathological addiction to sports are on the rise (cf. Agliata \& Tantleff-Dunn 2004, Shields \& Heinecken 2002). This illustrates that the way the body is talked about in public has consequences for how the body is subjectively felt by individual people.

Linguistic insights concerning the gendered body are scarce and often form parts of larger research projects that treat the body as just one aspect among many others. The studies to be found belong to three groups: (i) studies of genital vocabulary (e.g., Braun \& Kitzinger 2001a, 2001b; Cameron 1992), (ii) studies that investigate how speaking about the body contributes to gender performance (Guendouzi 2004 on female conversations on body size; Schmid 2003 on BNC data; Strong 2003 on bodybuilding language), (iii) studies dealing with the use of body-part terms as pars pro toto in specific text genres (Bolton 1995 on gay male erotic literature; Sveen 2005 on children's fiction; Wyss 2002a, 2002b on love letters). Nearly all of these studies (except Wyss 2002a, 2002b) look at Englishlanguage material, which makes English the best-documented language with respect to the linguistic construction of the gendered body. The following analysis will concentrate on the latter aspect - body-part vocabulary as a synecdoche for whole persons, but the other two areas will also play a role.

GENDER CONSTRUCTION VIA B ODY-PART V OCABUlary

Before diving into advertising discourse proper, it is worthwhile to point out gendering mechanisms as they are at work in body-part vocabulary. Personal nouns 
serve as a reference point here because they undoubtedly are the realm in which linguistic gender construction has been explored most comprehensively (cf. contributions in Hellinger \& Bussmann 2001-2003; Hornscheidt 2006). As the data discussed later exclusively consist of English language material, the discussion will be restricted to those mechanisms of linguistic gender construction relevant to English. According to Hellinger \& Bussmann 2001, these are LEXICAL, SOCIAL, AND REFERENTIAL GENDER. ${ }^{1}$

Personal nouns show LEXICAL GENDER when they carry the semantic feature [female] or [male]. Most languages have certain sets of personal nouns that are particularly likely to be lexically gendered. This is usually true for kinship terms (e.g., mother, father; brother, sister), address terms (Mr., Mrs., Miss, Ms.) and personal nouns denoting female and male human beings in general (woman, man; boy, girl). From a lexical point of view, most personal nouns in English are gender-indifferent; that is, they carry neither the semantic feature [female] nor [male] (e.g., person, nurse, farmer). For body-part vocabulary, a similar mechanism is in operation for those lexical items that denote primary and secondary physical gender characteristics. Lexemes such as vagina, penis, beard, and breast therefore have roughly the same impact on discourse gendering as personal nouns like woman, man, girl, and boy; that is, they are direct gender indexes (Ochs 1992). In other words, lexical gender is about categorizing the gender continuum into two and only two binary macro-categories, "female" and "male".

The fact that lexically gender-indifferent personal nouns like nurse and farmer are anything but completely gender-neutral is a matter of SOCIAL GENDER. Whereas nurse is more likely to be perceived as female, farmer is biased toward the male. Phenomena like these are sometimes also called COVERT GENDER (see Hellinger 2004) because gendering in these cases cannot be deduced from the forms themselves, but surfaces only occasionally - for instance, when anaphoric pronouns refer to the personal nouns concerned (e.g., nurse - she; farmer - he). Social gender is a matter of entrenched social stereotypes that tie certain role scripts to women and men. These stereotypes can be very well established (as is the case for nurse and farmer), but they may also come in much weaker degrees of stereotypical association (teacher and doctor are certainly less clearly socially gendered; see Kennison \& Trofe 2003). Again one could argue that similar mechanisms pertain to body-part terms that denote neither primary nor secondary physical gender characteristics, but that are nevertheless stereotypically associated with the (ideal) female or male body. Muscle, for instance, would certainly be a candidate for male social gender, whereas eyelash could be seen as socially female gendered. We might also suspect that muscle and eyelash are more clearly socially gendered than back and skin. Social gender, therefore, is not about directly indexing female or male, but about making a gendered interpretation more likely (indirect gender indexing).

REFERENTIAL GENDER is a matter of whom a particular personal noun actually refers to in a given context. From a deconstructionist point of view, this certainly 
is the most valuable gender category because it is able to acknowledge more subversive practices of gender symbolization that do not correspond to hegemonic gender norms. Accordingly, lexically female personal nouns can in certain contexts also be used to refer to men, and vice versa. This is not uncommon in gay male discourse (see Baker 2002 on Polari; Johnsen 2001). Another example would be cases of male generics ${ }^{2}$ that have been criticized by feminist linguists as sexist (e.g., chairman when referring to a woman). Referential gender in body-part lexemes again shows great similarities with personal nouns. Depending on the context, lexically and socially gendered body-part terms can, of course, refer to female as well as male bodies. This is straightforward with socially gendered body parts. You can talk about a man's eyelashes or a woman's muscles relatively easily (even if these body parts might not be the first ones to think of when imagining a stereotypical female or male body). This would correspond to cases where socially gendered personal nouns like farmer and nurse actually refer to women and men respectively in a specific context. With respect to lexically gendered nouns, the point of comparison would be, for example, subversive uses of terms like girl or sister in gay male contexts. Talking about a particular woman's beard or a particular man's breast might seem unusual, but this is the case because talking about these is as similar a taboo topic as is addressing a man as girl in most contexts. There are, of course, women who grow a beard and men who have larger breasts than some women, even though these are body practices that are usually avoided, hidden, and not talked about. Bearing transgender identities in mind, it is even thinkable to talk about a particular man's vagina or a particular woman's penis.

THEORETICA L CONSIDERATION S

\section{A poststructuralist approach to gender}

Language and gender studies is a discipline that has grown steadily since its inception in the 1970s. In the course of time, several research strands have evolved. The most prominent ones are known under such key words as DOMINANCE (e.g., Lakoff 1975), DifFERENCE (e.g., Tannen 1990), COMMUNiTy OF PRACTICE (e.g., Eckert \& McConnell-Ginet 1992), BEYOND BINARY THINKING (e.g., Bing \& Bergvall 1996) or DOING GENDER (e.g., Gottburgsen 2000). Especially the latter two can be seen as a move toward poststructuralist thinking in gender research that also has gained ground in gender linguistics in recent years (see, e.g., Baxter 2003 on Feminist Poststructuralist Discourse Analysis; Speer 2005 on Conversation Analysis). Much of this work has been influenced by Butler's (1990, 1993, 2004) theorization of gender, which, in turn, is heavily indebted to poststructuralism, social constructionism, and deconstructionism. Central aspects in this line of theorization include a conceptualization of gender as a performative ritualized practice that has evolved through infinite citation and re-citation, a motivation to question gender (and other essentialist categories) in its binary makeup, a focus on 
the subversion of hegemonic identity categories, and therefore a clearly problematizing agenda. Poststructuralist work has often been criticized for providing a highly theoretical approach to gender without any connection to everyday practices (see Speer 2005:67). Sociolinguistics could be one of the disciplines to build a bridge between those abstract theorizations of gender and what they actually mean in concrete communication situations, not least because the concepts of "language," "linguistic turn," and "discourse" figure prominently in poststructuralist debates.

The approach used here for the discussion of linguistic gendering via body-part vocabulary in advertising discourse is deconstructionist in the sense that the concept of a prediscursively existing female or male body is questioned, and similarity, rather than fundamental difference, of female and male bodies is taken as the basic assumption. Approaches like these clash drastically with how laypersons (and mainstream advertising) treat gender - as a clear-cut, natural, and immutable category to be read from the body. People voicing the need to escape these categories are judged to be deviant, if not pathological. Accordingly, it is hegemonic gender norms in the form of prescribed body practices that are to be questioned here. Using the categories of lexical, social, and referential gender for the analysis of body-part terminology might be seen as too firmly based in structural linguistics to be compatible with a deconstructionist approach. However, it is exactly with these categories that binary gender conceptualization can be questioned (Motschenbacher 2008b). Their coexistence bears witness to a sophisticated way of dealing with linguistic gendering that responds to more traditional approaches that declare English, for instance, to be a language with "natural gender" - an approach often found in foreign language teaching or basic grammars despite its inability to deal with gendering mechanisms in those personal nouns (and, by extension, body-part terms) that either are not lexically gendered or show a mismatch between lexical and referential gender in an actual communication context.

\section{Gender, discourse and linguistic performativity}

In a poststructuralist approach, linguistic gendering cannot be associated with the notion of a variety defined according to user (such as dialect, sociolect, idiolect). In accordance with the view of gender as performative, it makes more sense to compare linguistic gendering with varieties defined according to use (such as registers and styles) - that is, varieties used for performing gender (not varieties of women and men). This precludes basing linguistic gender theorization on women and men as preexisting identity categories and respects the fact that gender is constructed in the very moment of language use. Moreover, this procedure allows for a more diversified and contextual conceptualization of gender than would a strictly binary model of female versus male variety. The basic assumption here is that a plurality of femininities, masculinities, or androgynies can be (linguistically) performed. These may vary interpersonally and intrapersonally. In fact, 
they are not even tied to the notion of "a person" or a "speaking/writing subject" as such, which is very graphically illustrated by advertising.

Commercial texts are created by a copywriter or a whole team of copywriters in close cooperation with the respective product company. Nevertheless, the identity constructions to be found in advertising can hardly be said to be a reflection of the authors' identities. In advertisements, identities are strategically constructed to appeal to certain target groups. That language can be exploited to that aim is not sufficiently explained through performance. This mechanism has to be seen from a wider, macro-social perspective that acknowledges the role of ideologies and dominant discourses. The dependency of linguistic identity constructions on discourse, in the Foucauldian sense of "practices that systematically form the objects of which they speak" (Foucault 1972:49), therefore, is a matter not of performance but of performativity (Austin 1962; see also the distinction between "construal" and "construction" in Fairclough 2003:8). That gender identities can be linguistically evoked can work only because individual performances are embedded in an infinite history of continuing citation and re-citation, in which they have achieved the status of hegemonic dicourses that defy the notion of a specific, personal origin (Butler 1990, 1993). When dealing with performativity rather than with performance, agency is no longer central. What is more important here is the performative indexicality of linguistic signs, a property that might be inflected by context.

Most studies in language and gender research have concentrated on individual gender performances, while very few have tried to tackle performativity as it relates to language practices. The field of language and sexuality, however, has recently witnessed academic attempts to overcome this deficit. The central question, then, is no longer "Who says something?" but "What does saying something produce?" An excellent study to demonstrate this is Kulick's (2003) analysis of the meaning of the word no in sexualized contexts. Refusal of sexual advances in heterosexual courtship has a performative history that is responsible for the fact that somebody who says no in sexual interactions is subjected to a female subject position, whereas for hegemonic male identities, yes would be the unmarked response. As women in accordance with this dominant discourse are not supposed to consent to sex if they do not want to be labeled sluts, no has acquired a dual indexicality, meaning "refusal" on the level of performance, but "maybe" or "keep trying" on the level of performativity. This dual indexicality is exploited in various sexually relevant contexts. It enables male rapists to claim that their female victims have not effectively communicated refusal. It gives male perpetrators of homosexual panic attacks the chance to justify their crime, implying that forcing a man to say no to sexual advances from another man bestows a female subject position on him - an act that is strategically likened to an attack that would legitimate self-defense. Finally, it can be used in sadomasochistic sexual practice as a way of performing the illusion of resistance for the sake of heightened pleasure. 
Advertising texts that use body-part lexis to appeal to gendered target groups also exploit performativity. In a process of continuing re-citation, certain bodypart terms have reached the status of powerful indexes of the gendered body. In the case of lexically gendered body-part lexemes, discursive materialization has gone so far that they have become direct gender indexes. For socially gendered body-part terms, this materialization is somewhat less substantial, which makes them indirect indexes of the gendered body.

M E T H O D O L O G Y

A great deal of physical gender representation in advertising takes place visually through the picturing of bodies and body parts. However, the focus of the following work (material taken from Motschenbacher 2006; see also Motschenbacher 2008a, 2008c) will be specifically on the linguistic construction of the body to demonstrate that gender symbolization also works on a linguistic plane in advertising - a subject that has so far been studied insufficiently (for a detailed research overview, see Motschenbacher 2006:50-56). Compared to iconic visual body representation, language constructs the body through symbolic signs. This results in a more abstract representation in which the diverse visual realization types of body parts - for instance, heads of various shapes (among them more female and more male head shapes) - would all be subsumed under a single linguistic sign head (which in turn may be disambiguated through the interplay between language and illustration in an advertisement or by contextual cues in general). Moreover, language facilitates the representation of body parts located inside the human body, which usually are less easily accessible and therefore more difficult to represent visually by means of a photograph. The following analysis will show that even relatively abstract linguistic body construction plays a significant role in gendering advertising texts.

For the purpose of the study, material was gathered from two general-interest lifestyle magazines that differ mainly with respect to their gendered target groups: Cosmopolitan and Men's Health (for research on these two titles, see Alexander 2003, Machin \& Thornborrow 2003). The reason for choosing a women's and a men's magazine was to ensure a context of high gender salience in which the features identified can be more plausibly related to gender than in gender-undifferentiated magazines. However, the present study does not intend to make general assumptions about the genre of women's and men's magazines, but specifically about the two synthetic communities of Cosmopolitan and Men's Health. Both magazines are monthly glossies with a core target group roughly described as young (core: 25-35 years) and middle-class (core: $\mathrm{ABC}_{1}$ ). Furthermore, both belong among the most successful titles of their kind and are published in many international editions, creating a worldwide virtual community of readers. On a content level, the two magazines are very similar, both covering topics such as appearance, sports, relationships, fashion, cooking, and sex (for more details, see 
Cosmopolitan 2003, Men's Health 2003, and information on the two magazines in Gauntlett 2002 and Striplin 2000).

Magazine genres are stereotypically gendered. Those traditionally considered men's magazines tend to focus on cars, sports, or erotica. Consequently, the male self-image is not a central topic in these magazines. The general-interest magazine sector, however, is traditionally female in association, which makes lifestyle magazines for men relatively exceptional. The advantage of choosing Men's Health for a comparison with Cosmopolitan lies primarily in the fact that the former focuses on the male self-image as opposed to other men's magazines, which in turn brings it closer to the format of women's magazines:

Indeed, the central difference between Men's Health and a women's magazine such as Cosmopolitan is that the former promotes a hard body and the latter promotes a thin body. With this exception, these snippets on diet and fat reduction ... could easily appear on the cover of a women's magazine. (Alexander 2003:542)

The title Men's Health is actually misleading. It can be interpreted as a strategic move to get men to buy a general-interest magazine that in many respects is similar to a "typical" women's magazine. For the purposes of the linguistic analysis, the makeup of these magazines ensures that body-part terms in Cosmopolitan almost exclusively describe the female body and those in Men's Health the male body. ${ }^{3}$

The text corpus on which the study is based consists of 2,000 advertising texts (source: half UK and half US editions of the two magazines, January 1999 to September 2001), amounting in total to more than 175,000 words. As the focus of the study was on advertising language, magazine issues were examined to include the first 1,000 excerpts from each title that possessed at least one of the prototypical parts of an advertisement (headline, body copy, or slogan). All advertisements that were exclusively visual or merely showed the name of the brand or product as their only verbal elements were not included in the corpus. Otherwise, there were no restrictions for inclusion, which ensures that texts advertising a broad range of product groups are under scrutiny. Corresponding to the two target groups, the corpus contains two sub-corpora (Cosmo and $\mathrm{MH}^{4}$ ) to be consulted for crossgender comparison. Advertising texts show a high degree of variation in typeface and very often are anything but a continuing stretch of text. Since this made scanning impossible, all advertisements had to be typed by hand. For the purpose of analyzing linguistic body representation, an inductive approach was chosen: All advertisements in the corpus had to be looked through individually in order to identify all words that refer to the body or parts of the body in the widest possible sense. All body terms collected were afterwards quantified by using the corpus analysis software WordCruncher.

It was necessary to inspect all body-part lexemes in the corpus individually because a mere quantification would - in some cases - not have been able fully to capture gendering mechanisms. This can be illustrated by the distribution of the 
lexeme blister. Blisters can affect various parts of the body. The overall frequencies of the lexeme ( $\mathrm{f} 7-\mathrm{m} 11$; $\mathrm{f}$ and $\mathrm{m}$ in the following indicate absolute figures in Cosmo and $M H$ ) point to a roughly equal distribution. Depending on the magazine at hand, however, blister is clearly more likely to refer to blisters on one's lips in Cosmo (f6- m0) and to blisters on one's feet in $M H$ ( $\mathrm{f} 1-\mathrm{m} 11)$.

All instances in which body-part lexemes did not actually refer to a part of the human body (e.g., arms when talking about the parts of a technical device or figure when talking about numbers) were eliminated from the final frequency calculation. Statistical significance was tested using a chi²-test. In the following tables and figures, $\mathrm{F}^{*}$ indicates features that occur significantly more often in Cosmo and $\mathrm{M}^{*}$ those that occur significantly more often in $M H$. Differences were declared significant in cases in which the likelihood of error is less than $5 \%(\mathrm{p}<0,05)$. Finally, all terms collected were classified and arranged into the following lexical fields (see Lehrer 1974): body tissue, limbs, hair, skin, hormones, head, muscles, inner organs, trunk, skeleton, ligaments/sinews/nerves/blood vessels. ${ }^{5}$ The quantitative procedure is combined with qualitative analyses of the use of body-part lexemes in specific advertisements. This provides a more sophisticated picture of linguistic gendering through body-part vocabulary than a merely qualitative study of a few selected advertisements could achieve. Quantification enables researchers to make statements about the performativity value certain lexical items have. The greater the difference of distribution between Cosmo and $\mathrm{MH}$, the more dominant the respective gendered discourse of which the body-part lexeme is a trace. It is important, however, that the differences retrieved here cannot stand for the entire macro-categories "female" and "male." Instead, they represent gendering mechanisms and dominant discourses relevant for two specific communities and must not be directly transferred to huge target groups of all women or all men.

The following research questions will guide the analysis: Does body representation in advertising language contribute to a gendered discourse in the two magazines analyzed? If so, how is this achieved? Which parts of the body seem to be more and which less involved in gender performance? How does the lexical, social, and referential gender of body-part terms play a role in this process?

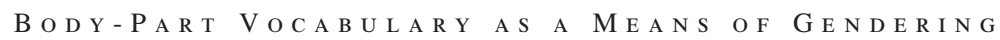

A D VERTISING TEXTS

\section{Gendered body ideals in advertising}

As advertising is always under the pressure to appeal to potential consumers, the femininities and masculinities found in Cosmopolitan and Men's Health must be considered maximally intelligible for the target group at hand and therefore highly stereotypical. This may result in a bleak picture as far as social progressiveness is concerned. But it is important to see these practices not as representations of masculinity and femininity per se, but of specific forms of masculinity and femininity 
that might differ from the intelligibility norms of other target groups (compare, for instance, the female role model constructed in a feminist magazine such as Ms. versus Cosmopolitan, or the male role model in a gay male magazine such as Attitude versus Men's Health). What might be universal about gendered representational practices in advertising is the fact that all of them are extremely normative and (more or less explicitly) require recipients to engage in gendering work (through consumption of the products advertised) in order to pass as a "real" woman or man. Thus, it is not makeup or a car that is offered, but femininity and masculinity via these products. Talking more specifically about body terminology, advertising - in its own interests - sets body standards to live up to and tries to manipulate recipients into thinking that their bodies are less than perfect. This is illustrated by the following example from an advertisement for women's underwear:

(1) introducing shape $f x^{\mathrm{TM}}$

... designed to make the body you have look like the body you want ${ }^{\mathrm{TM}}$

(Cosmopolitan US, 10/1999:161)

When looking at lexemes denoting "body shape" in the advertising corpus, it becomes immediately clear that gendered body symbolization in this context resembles a binary rather than a continual representation. The word physique is used exclusively in $M H$ (17 times), whereas figure is used seven times in Cosmo and only once in $M H$. Physique is associated with muscularity and athleticism, while figure has connotations of daintiness and beauty. The following examples illustrate how these words are used for the construction of the female body in Cosmo and the male body in $M H$ :

(2) Take control over your physique

Thermobol is Maximuscles [sic] best selling herbal supplement.

SPECIAL OFFER: For one month only we are giving away a comprehensive Fat Loss Get In Shape Guide written by acclaimed nutritionist Zef Eisenberg to help you achieve your physique goals.

(Men's Health UK, 09/2001:154)

(3) Every woman, at some time, will experience concern about her figure, mainly because of the slackening of the skin and appearances of Cellulites and stretch marks, storing excess fat on hips, stomach and thighs, resulting in a dimpled look.

(Cosmopolitan US, 03/2000:292)

Another aspect of the linguistic treatment of the female and male body that surfaces here is the relationship the recipient is suggested to have with his or her body. Describing a woman's figure in Cosmo often resembles self-consciously dealing with problem areas, whereas in $M H$ the male physique is seen as a challenge that real men have to face. Prototypical visual representations of physique and figure typically appear on the covers of the two magazines.

To test whether body ideals play an equally important role in both magazines, all instances of the word body in the corpus were identified, distinguishing uses in compounds, in product names and on its own (see Table 1). Generally speaking, 
TABLE 1. Instances of the word body in Cosmo and $M H$

\begin{tabular}{lcrc}
\hline \hline & Cosmo & MH & Significance \\
\hline body (on its own) & 86 & 135 & $\mathrm{M}^{*}$ \\
Compounds containing body & 67 & 71 & \\
Product names containing body & 10 & 31 & $\mathrm{M}^{*}$ \\
Total & 163 & 237 & \\
\hline \hline
\end{tabular}

body is a common lexeme in both sub-corpora. The difference between Cosmo (163 instances) and $M H$ (237 instances) is not significant and shows that nowadays not only women are normatively required to take care of their bodies. This is even more evident when one looks at instances of body on its own and in product names, which can be found significantly more often in $M H$.

Quantitatively, there is no difference in the amount of body-compounds used in Cosmo and $M H$. A closer look at the kinds of compounds that occur, however, points to an essential qualitative difference (see Table 2). Compounds belonging to the semantic domain "personal hygiene" (such as body wash, body lotion or body spray) occur considerably more often in Cosmo, whereas those belonging to the domain of "sports" occur almost exclusively ${ }^{6}$ in $M H$. This suggests that the supposed path to the ideal body differs for women and men. According to advertising, women are supposed to adorn and beautify their bodies, while men are supposed to exercise them.

\section{Linguistic gendering via body-part vocabulary}

The next step of the analysis was to study the way body-part vocabulary contributes to the gendering of advertising texts. The following discussion will concentrate on a selection of six lexical fields that are most interesting with respect to gender performance: "limbs," "hair," "skin," "face" (as a sub-field of "head"),

TABLE 2. Distribution of body-compounds

\begin{tabular}{|c|c|c|c|}
\hline & Cosmo & $M H$ & \\
\hline \multirow[t]{2}{*}{$\begin{array}{l}\text { Domain } \\
\text { "personal } \\
\text { hygiene" }\end{array}$} & $\begin{array}{l}\text { body wash (11), body lotion (4), body oil } \\
\text { (2), body mist (2), body spray (2), body } \\
\text { moisturiser, body loofah, body } \\
\text { cleansers, body cream }\end{array}$ & $\begin{array}{l}\text { bodycare (2), body wash, body lotion, } \\
\quad \text { body scrub }\end{array}$ & \\
\hline & [total: 25$]$ & [total: 5] & $\mathrm{F}^{*}$ \\
\hline \multirow[t]{2}{*}{$\begin{array}{l}\text { Domain } \\
\text { "sport", }\end{array}$} & bodybuilding & $\begin{array}{l}\text { body massage (3), body conditioning } \\
\text { (2), bodybuilding (2), body workout } \\
\text { (2), bodybuilder, bodytone, body } \\
\text { trainer, body fitness }\end{array}$ & \\
\hline & [total: 1] & [total: 13] & $\mathbf{M}^{*}$ \\
\hline
\end{tabular}


"muscles," and "trunk." These fields are the ones with the highest overall frequencies, and most of their field members represent body parts that are neither primary nor secondary physical gender characteristics.

Two types of semantic relation are essential for establishing the lexical fields of body parts. The first is HYPONYMY, which refers to a "kind of" relationship in the taxonomical hierarchy; thus, the hyponyms abdominals, biceps, and triceps are kinds of muscles (=hyperonym). Hyponyms are semantically more specific than their hyperonyms because they possess an additional semantic feature (compared to muscle, hyponyms such as biceps indicate the position of the muscle on the body). The second relation type is MERONYMY, which means a part-to-whole relationship; thus, the meronyms thumb, index finger, middle finger, etc. are parts of the hand (=holonym). In the following figures, a meronymic relationship will be symbolized by a solid line, whereas hyponymic relations will be indicated by a broken line. Lexical fields that are completely hyponymic in their structure will be represented as tables. Figures following $\mathrm{f}$ and $\mathrm{m}$ indicate absolute frequencies in Cosmo and $M H$ respectively. Adjectival, plural, and other inflected forms are noted in brackets if they occur additionally to the base form in the corpus. In cases where only an inflected form exists in the corpus, this form is also used as a representation in the lexical field. Lexical items that do not actually occur in the corpus but are necessary for the internal structure of the lexical field are given in square brackets.

The lexical field "limbs" (see Figure 1) falls into two halves: "arm" and "leg." In the first half, an equal distribution between the two sub-corpora can be found as

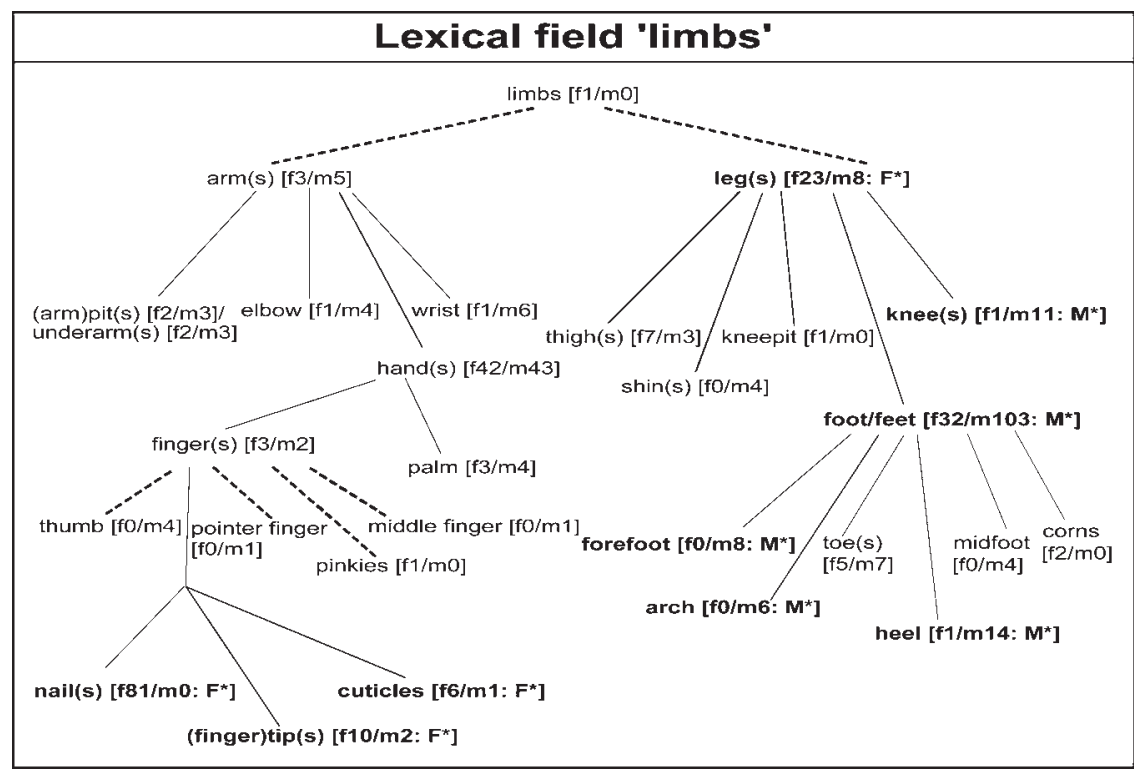

FIGURE 1: Lexical field "limbs" 
far as arm, arm parts, hand, hand parts, and kinds of fingers are concerned. When it comes to finger parts, however, a heavy concentration in Cosmo can be detected, which is true for cuticles ( $\mathrm{f} 6-\mathrm{m} 1)$, (finger)tip ( $110-\mathrm{m} 2$ ) and especially nail $(\mathrm{f} 81-\mathrm{m} 0)$. This resembles a drastic binary gender construction, considering that all healthy human beings possess cuticles, fingertips, and fingernails, no matter what their gender. We can deduce from this that finger parts seem to play an important role for the symbolization of the ideal female body in Cosmo, but not of the male body in $\mathrm{MH}$. A higher concentration in Cosmo can also be found for leg (f23 $-\mathrm{m} 8$ ). On the other side, the leg parts knee (f1 - m11) and foot (f32- m103) occur significantly more often in $M H$, together with the foot parts forefoot (fo $-\mathrm{m} 8)$, arch (f0 - m6), and heel (f1 - m14). These body parts are important for the construction of the male body in $M H$ because they are functionally essential for doing sports:

(4) [...] Yeah, you wouldn't think it at first, but those shin splints, those tender knees, that pain in your lower back? All of those problems could find their root right down in your feet. If your feet hit the ground unevenly, you could cause a chain reaction that starts in your feet and can go all the way up through your lower back.

Dr. Scholl's experts know this. We also know about a lot of other problems that plague active men; like arch pain, aching heels and blisters. That's why we've designed a line of athletic-specific products that will help you perform at your best. [...] (Men's Health US, 07/1999:73)

In order to grasp how the lexical field "hair" (see Figure 2) contributes to gender construction, one has to distinguish between different types of hair, because they are related differently to the ideal female and male body. Dominant gender discourses set long head hair as a feminine beauty ideal, whereas men typically are supposed to wear short hair. Contrary to this, hair on other parts of the body is extremely stigmatized for the ideal female body, but may even be a sign of "true" masculinity for the male body. This is evident in the following example, in which

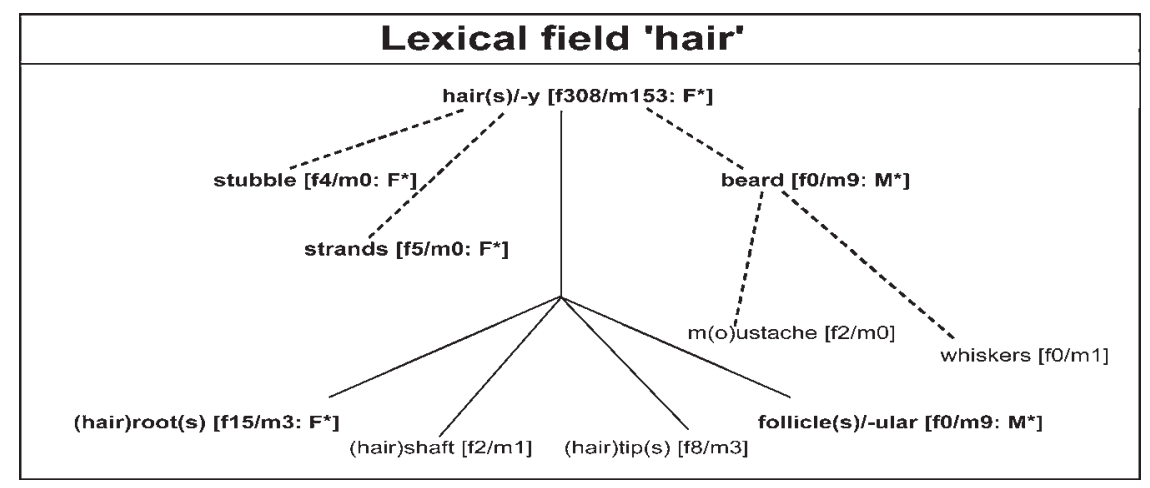

FIGURE 2: Lexical field "hair" 
stereotypically masculine chest hair is transferred to the product (a car) and femininity is explicitly ruled out:

(5) IT DOESN'T HAVE A FEMININE SIDE TO GET IN TOUCH WITH.

The new Nissan Frontier. Factory-installed, supercharged V6. 210 horsepower. Aggressive new design. If it had a chest, it'd be hairy.

(Men's Health US, 07/2001:16-17)

The high frequency of hair (f308 - m153) in Cosmo is due to the positive symbolization of long female scalp hair (see also strands and the somewhat higher frequencies of hair root and hair tip in Cosmo, which also point to long hair) as well as the negative symbolization of female body hair. Beard ( $\mathrm{f0}-\mathrm{m} 9)$ occurs exclusively in $M H$, which is in accordance with seeing the beard as a secondary physical gender characteristic (even though women might grow beards as well). The exclusive use of follicle ( $\mathrm{fO}-\mathrm{m} 9$ ) in $\mathrm{MH}$ can be explained by the fact that baldness is seen as a stereotypically male characteristic (even though there are women who suffer from hair loss). At first glance, it might seem strange that stubble and $m(o)$ ustache can be found only in Cosmo because when judged in isolation, they are more likely to be associated with male facial hair. A closer look at the contexts in which these lexemes are used in Cosmo shows that they allow advertisers to construct decidedly negative female body images, connecting stereotypically masculine body characteristics with improper femininity:

(6) If the mustache that prevents you from getting close is yours (not his), it may be time for a beauty about face. Millions of women like yourself battle unwanted facial hair. But no matter how many times you win the fight, the enemy just keeps coming back - and always too soon. Don't you think it's time for some new ammunition!?! (Cosmopolitan US, 01/2001:33ff)

The lexical field "skin" (see Figure 3) is extremely important for the construction of the female body in Cosmo. Nearly all field members show higher absolute

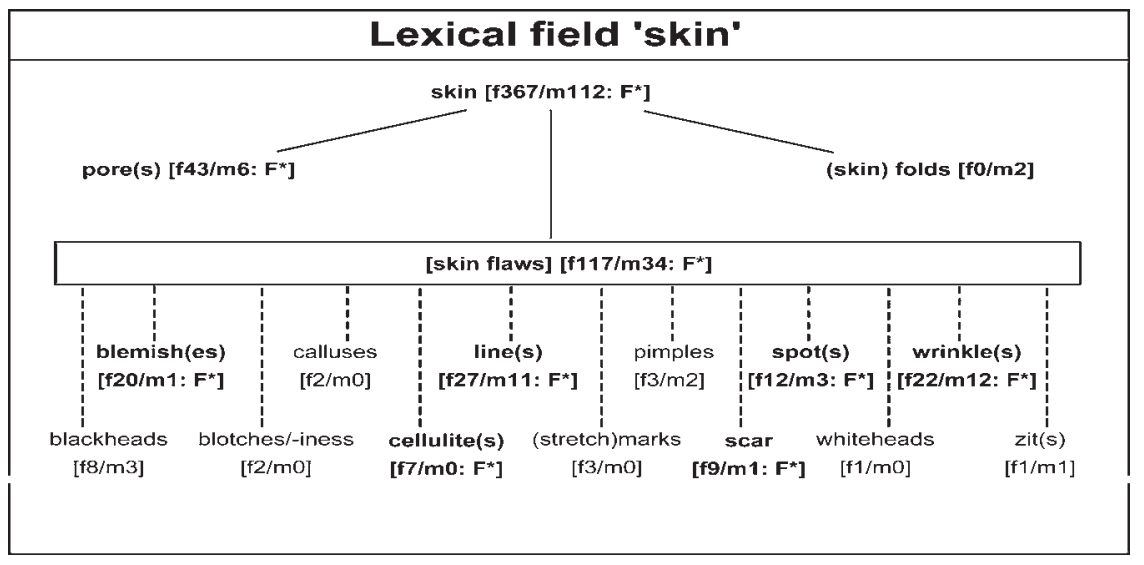

FIGURE 3: Lexical field "skin" 
frequencies there. This is especially true for the holonym skin (f367 - m112), pore (f43 - m6), and skin flaws in general (f117 - m34), which make up a relevant proportion of the field. It is obvious from looking at this field that especially the female body is symbolized by negative body images and lexemes such as blemish, cellulite, line, scar, spot, or wrinkle. This trend is also supported by the distribution of lexemes referring to body flaws without being restricted to a particular area of the body (i.e., flaw, imperfection, and problem areas occur exclusively in Cosmo).

In the lexical field "head," most head parts show an equal distribution between the two sub-corpora. Exceptions can be found, however, in the sub-field "face," which again is an area of considerable importance for the female body ideal in Cosmo (see Figure 4). Significantly higher frequencies in Cosmo can be verified for the holonym face/facial (f89/m51), the face parts lip (f149- m0), eye (f102 $\mathrm{m} 59)$ and chin (f4 - m0) and finally the eye parts lash (f37 - m0) and brow (f4 $\mathrm{m} 0$ ). The exclusive occurrence of lip and lash in Cosmo again bears witness to a strictly binary gender construction. Although both women and men possess lips and lashes, they play a central role in the staging of seductive femininity:

(7) Lips that shine. Hydration that lasts.

BRILLIANT MAGNÉTIC/ SHEER LIP-COLOUR, WEIGHTLESS COMFORT.

NEW/ The Ultra-Shine $@$ film makes your lips glisten with fresh, kissable colour. Sheer

brilliance. RESULT: 10 shades for supple, hydrated and luscious lips.

BELIEVE IN BEAUTY

LANCÔME PARIS. (Cosmopolitan UK, 07/2000:10-11)

(8) It's a Curlier, Flirtier Lash!

MAYBELLINE WonderCurl mascara ${ }^{\mathrm{TM}}$

Only Maybelline could make a curl this captivating!

CURL-ACTIVATOR BRUSH/grabs and curls lashes

ELASTIC FORMULA/ lengthens and sets the curl

NEW/ now in Waterproof! (Cosmopolitan US, 07/1999:13)

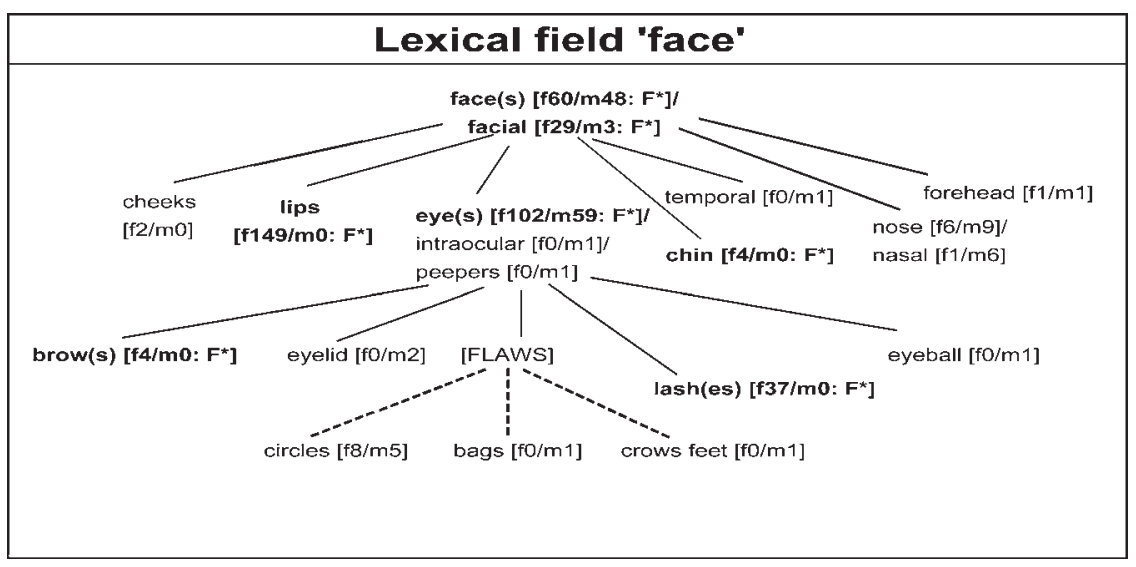

FIGURE 4: Lexical sub-field "face" 
The lexical field "muscles" (see Table 3) - in accordance with gender stereotypes is clearly more important for the construction of the ideal male body in Men's Health than is any other field. The hyperonym muscle/muscular occurs 135 times in $M H$ and only 9 times in Cosmo. Specific kinds of muscles are differentiated exclusively in $M H$. All of the lexemes denoting muscle types can be considered typical of bodybuilding language and have the function of desexualizing the male gaze on the male body (cf. Strong 2003). Abductor hallucis, quadratus plantae, and opponens digiti minimi are Latin technical terms for specific foot muscles. More informal in nature are six-pack and the clippings abs and quads (<abdominals, quadriceps). This lexical field as a whole constructs the male body ideal as "masculinity equals muscularity" and is in $M H$ always connected to heterosexual masculinity:

(9) NEW NATURAL SHORTCUT TO THE PERFECT SIX PACK NATURALLY PACKED

Scientists have finally come up with a revolutionary formula to help you get those muscles girls go crazy for, the easy way! These days, high fashion is all about looking good with your clothes off as with them on - and that means working your body to get that mean, lean, hard look! (Men's Health UK, 01/1999:143)

The final lexical field to be treated in detail is "trunk" (see Figure 5). This field is particularly relevant for gender construction because here lie what are widely known as primary physical gender characteristics. Even though the term genital does not occur in the entire corpus (therefore given here in square brackets), lexemes denoting genital types are confined to one of the two sub-corpora, constructing a strictly binary biological basis for gender differentiation: vagina ( $\mathrm{f} 6-\mathrm{m} 0)$, prostate $(\mathrm{f} 0-\mathrm{m} 20)$, testicle $(\mathrm{f} 0-\mathrm{m} 3)$, ball $(\mathrm{f} 0-\mathrm{m} 1) .{ }^{7}$ The fact that back occurs significantly more often in $M H$ reminds us of the stereotype of the hard-working man whose back is aching. Bikini line ( $\mathrm{f} 7-\mathrm{m} 0$ ) obtains its female association primarily because a bikini is a typically female piece of clothing. For referring to the same region of the male body, other terms (groin, lumbar) would normally be

TABLE 3: Lexical field "muscles"

\begin{tabular}{lccc}
\hline \hline & Cosmo & MH & Significance \\
\hline muscle(s)/muscular & 9 & 135 & $\mathrm{M}^{*}$ \\
MUSCLE TYPES: & 0 & 5 & $\mathrm{M}^{*}$ \\
abs & 0 & 2 & \\
biceps & 0 & 3 & $\mathrm{M}^{*}$ \\
quad(s) & 0 & 6 & \\
six(-)pack & 0 & 1 & \\
triceps & 0 & 1 & $\mathrm{M}^{*}$ \\
Abductor Hallucis & 0 & 1 & 1 \\
Quadratus Plantae & 0 & 20 & \\
Opponens Digiti Minimi & 0 & & \\
Muscle types total & &
\end{tabular}




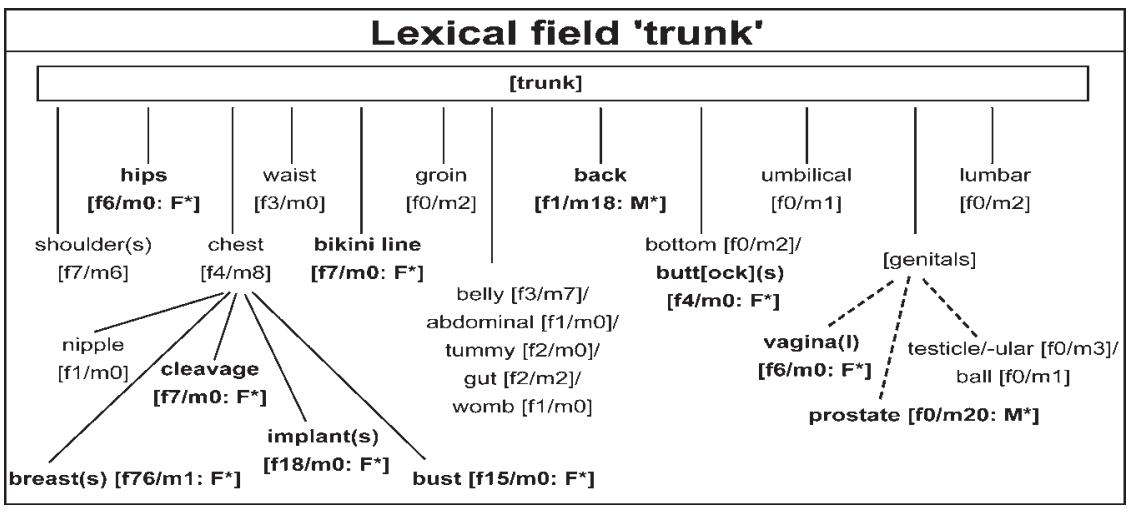

FIGURE 5: Lexical field "trunk"

used in $M H$. The lexemes breast (f76 - m1), cleavage (f7 - m0), bust (f15- $\mathrm{m} 0$ ) and implant $^{8}(\mathrm{f} 18-\mathrm{m} 0$ ) represent secondary female body characteristics and occur almost exclusively in Cosmo. Together with hip (f6 - m0) and butt/buttock $(\mathrm{f} 4-\mathrm{m} 0$ ), they sketch a stereotypically curved silhouette of the ideal female body.

\section{Summary of findings}

The analysis of body lexis used in advertising from Cosmopolitan and Men's Health has revealed that the linguistic representation of the body is clearly structured in accordance with dominant gender discourses that are strategically deployed to normatively construct female and male bodies. This is achieved through all three kinds of gendering mechanisms relevant for English: lexical, social, and referential gender. Even though referential gender was not specifically addressed owing to the concentration on verbal gendering, it can be said with confidence that the vast majority of body-part lexemes refer to the female body in Cosmo and to the male body in $M H$. This can often be verified through the visual illustration or the verbal co-text of the advertisement (as the examples cited show). Mismatches between lexical and referential gender were rarely found and were used exclusively in Cosmo to construct negative female body images (cf. mustache). Lexically gendered body terminology (e.g., vagina, prostate; breast, beard) may lead to a direct gendering of the text, but it is responsible for only a relatively low percentage of body parts named. The highest proportion of discursive gendering is done by body-part vocabulary that is socially gendered. Even though all human beings may possess these body characteristics, they are nevertheless taken to be more typical for the construction of either the female or the male body. Mismatches between social and referential gender (e.g., the construction of female muscles or male eyelashes) are the exception rather than the rule. 
When one compares this stereotypical construction of the female and male body, a dichotomous picture evolves. Stereotypically female body parts are more likely (i) to be located on the surface of the body and (ii) to play a role in the aestheticization of the body (cf. the realms "hair," "skin," "face"; finger parts). Stereotypically male body parts, on the other hand, are more likely (i) to lie within the body and (ii) to be of functional value (either for sports or for the working of the body; e.g., realm "muscles," leg parts and foot parts, back). The latter point is further supported by a general overview of the lexical fields "inner organs" and "ligaments/sinews/nerves" (both not elaborated on here), which also are more prevalent in $M H$ (for details see Motschenbacher 2006:250f, 255). Linguistic body representations as found in Cosmo versus $M H$ generally bear witness to a higher objectification of the female body. Additionally, the female body was shown to be more often defined as a problem area with negative body images to enforce normative imperatives.

As far as social gender is concerned, it seems that those body terms that mainly contribute to the construction of the female body in Cosmo are more strongly socially gendered than the ones used in $M H$ for the construction of the male body (except for muscle). This intuition would have to be verified by psycholinguistic experiments (similar to those by Kennison \& Trofe 2003). It might well be that body parts overall are more female in their stereotypical association because the female body traditionally has been more objectified and fragmentized (see also Wyss 2002b). In contrast to the "people = male-bias" identified for personal nouns by Silveira 1980, which suggests that lexically gender-neutral personal nouns (such as person) are more likely to be perceived as referring to men, one then would have to acknowledge a "body = female-bias" for lexically gender-neutral body-part vocabulary.

The way the male body is treated in $M H$ is to be characterized as homophobic in the sense that possible associations with homosexual eroticism are avoided. Aestheticized body parts play a minor role for male body symbolization, and technical terms serve to keep the necessary emotional distance when talking about the male body (a trend that can also be verified for the adjectival body-part lexicon in general; see Motschenbacher 2006:256f).

C O N C L U S I O N

Gendered advertising language renders a brilliant example of the linguistic performativity of identities. It illustrates how identities can be strategically constructed even by purely verbal means and independently of the biological characteristics of a speaker/writer. This indicates that questions of authenticity are not necessarily relevant for identity construction.

Starting with the basic assumption that female and male bodies are more alike than different, the poststructuralist approach adopted here facilitates exposing the 
linguistic representation of physical gender difference as a discursive construction. Two elements that particularly question a biological component as the basis for successful gender performance are (i) the fact that the gendered body in Cosmo and $M H$ is mainly constructed through socially gendered body-part terms (as opposed to lexically gendered terms denoting primary and secondary physical gender characteristics), and (ii) the fact that binary gender construction was in some cases even more clear-cut for socially gendered body-part terms than for lexically gendered ones (e.g., high exclusive occurrence of nail, lip, and lash in Cosmo; high concentration of muscle in $M H$ vs. two exclusive occurrences of $m(o)$ ustache in Cosmo).

The findings of this study may in some details appear to be predictable, but this serves to support its overall argument that linguistic gendering through the use of body-part vocabulary is effective because of the gendered performativity associated with many body-part terms. Body-part lexemes share this gender-performative quality with personal nouns and other linguistic features that are stereotypically connected with how women and men speak. Their sociolinguistic theorization requires a step away from the traditional notion of a variety as tied to certain preexisting speaker identities. As suggested in Motschenbacher (2007), this necessitates a poststructuralist redefinition of GENDERLECT in accordance with gender performativity, which acknowledges a whole range of gender identities, is able to incorporate features such as personal nouns, body-part vocabulary, and Lakoff's (1975) "women's language,"9 and respects that the performative force of these features varies with context (i.e. in Cosmopolitan and Men's Health it is certainly much higher than in other contexts). The result is a much more complex picture than the notion of a gendered variety. To illustrate this with the example of "women's language": (i) Not all women use "women's language" in actual speech (let alone all of the time); (ii) not all people who use "women's language" are women; (iii) nevertheless, the features of "women's language" are powerful resources to linguistically index female identities (for whatever purpose), and because of their performative dependence on dominant discourses they will continue to do so for quite a long time, even if all women suddenly stop using them. Returning to bodypart lexis, one would accordingly have to state: (i) Not all men have well-defined muscles; (ii) not all people who have well-defined muscles are men; (iii) still, the term muscles will have the performative force to construct the male body in the foreseeable future.

Finally, it needs to be added that this performative mechanism is neither a matter of free choice (owing to its dependence on hegemonic discourses) nor of production only. For advertising, it works interactively, with the target audience involved in a process of co-construction that can be likened to Althusser's (1971) theorization of interpellation. In other words, gender construction is effective only if the recipient recognizes a performance as intelligibly gendered. This is also the point at which normativity might have a damaging influence on people's 
subjective image of their own bodies, which they may see as inadequate if they do not conform to commercially constructed bodies.

\section{N O T E S}

${ }^{1}$ For other languages, whose nominal lexicon is structured by the noun classes "feminine" and "masculine," grammatical gender may also be relevant for the construction of the gendered body. Just as female and male lexical gender of personal nouns tends to correspond in these languages with feminine and masculine grammatical gender, lexemes denoting genitals show a similar trend; that is, lexemes denoting female genitals tend to be grammatically feminine (e.g. Germ. die Scheide, die Vulva, die Vagina, die Klitoris), while lexemes denoting male genitals tend to be grammatically masculine (e.g. Germ. der Schwanz, der Penis, der Phallus). As far as German is concerned, there are only few exceptions, such as Germ. masculine der Kitzler 'clitoris' or poetic metaphorizations of the penis as a weapon (e.g. feminine die Lanze 'lance', neuter das Liebesschwert 'love sword').

${ }^{2}$ As Modern English does not have grammatical gender, it does not make sense to speak of "masculine generics" here. To avoid confusion, the terms "feminine" and "masculine" should be reserved for grammatical gender in gender languages only. Semantic aspects of gender representation, such as found in lexical, social, and referential gender, should be described by using the adjectives "female" and "male" (Hellinger \& Bußmann 2001).

${ }^{3}$ Men's Health's parallel magazine Women's Health did not exist at the time of data collection. It was launched in the U.S. in October 2005.

${ }^{4}$ The exact corpus size is 79,972 words for Cosmo and 95,559 words for $M H$.

${ }^{5}$ Ligaments, sinews, nerves, and blood vessels were combined as a single category because all of them can be said to be functional parts inside the body. Their frequencies are low.

${ }^{6}$ The only instance of bodybuilding in Cosmo explicitly refers to a man and therefore is not an example of female body construction.

${ }^{7}$ The use of ball involves a word play. The advertisement is for men's underwear and pictures a male body wearing underpants from chest to knees, claiming perfect ball control - a phrase usually associated with football.

${ }^{8}$ The term implant was included among parts of the chest because all uses in the corpus refer to breast implants.

${ }^{9}$ Besides body-part vocabulary, other gender-relevant linguistic features that might qualify as components of a poststructuralist genderlect were studied with respect to their function in advertising in Motschenbacher (2006): pronouns, personal nouns, linguistic sexism, questions, colour lexicon, sports vocabulary, adjectives of appraisal, intensifiers and hedges.

\section{REFERENCES}

Agliata, Daniel, \& Tantleff-Dunn, Stacey (2004). The impact of media exposure on males' body image. Journal of Social and Clinical Psychology 23:7-22.

Alexander, Susan M. (2003). Stylish hard bodies: Branded masculinity in Men's Health magazine. Sociological Perspectives 46:535-54.

Althusser, Louis (1971). Lenin and philosophy and other essays. New York: Monthly Review.

Austin, John L. (1962). How to do things with words. London: Oxford University Press.

Baker, Paul (2002). Polari: The lost language of gay men. London: Routledge.

Baxter, Judith (2003). Positioning gender in discourse: A feminist methodology. Basingstoke, UK: Palgrave Macmillan.

Bing, Janet M., \& Bergvall, Victoria L. (1996). The question of questions: Beyond binary thinking. In Victoria L. Bergvall, Janet M. Bing \& Alice F. Freed (eds.), Rethinking language and gender research: Theory and practice, 1-30. London: Longman. 


\section{SPEAKING THE GENDERED BODY}

Bolton, Ralph (1995). Sex talk: Bodies and behaviors in gay erotica. In William L. Leap (ed.), Beyond the lavender lexicon: Authenticity, imagination, and appropriation in lesbian and gay languages, 173-206. Luxembourg: Gordon \& Breach.

Braun, Virginia, \& Kitzinger, Celia (2001a). "Snatch," "hole," or "honey-pot”? Semantic categories and the problem of nonspecificity in female genital slang. Journal of Sex Research 38:146-58.

Sociolinguistics 5:214-32.

Butler, Judith (1990). Gender trouble: Feminism and the subversion of identity. New York: Routledge.

(1993). Bodies that matter: On the discursive limits of "sex". New York: Routledge.

(2004). Undoing gender. London: Routledge.

Cameron, Deborah (1992). Naming of parts: Gender, culture, and terms for the penis among American college students. American Speech 67:367-82.

Cosmopolitan (2003). Cosmopolitan UK Homepage: Cosmopolitan Media Pack. http://www.natmags. co.uk/magazines/magazine.asp?id=2 [accessed September 4, 2003].

Eckert, Penelope, \& McConnell-Ginet, Sally (1992). Think practically and look locally: Language and gender as community-based practice. Annual Review of Anthropology 21:461-90.

Fairclough, Norman (2003). Analysing discourse: Textual analysis for social research. London: Routledge.

Foucault, Michel (1972). The archaeology of knowledge. London: Routledge.

Gauntlett, David (2002). Media, gender, and identity: An introduction. London: Routledge.

Gottburgsen, Anja (2000). Stereotype Muster des sprachlichen Doing Gender. Eine empirische Untersuchung. Wiesbaden: Westdeutscher.

Guendouzi, Jackie (2004). "She's very slim": Talking about body-size in all-female interactions. Journal of Pragmatics 36:1635-53.

Hellinger, Marlis (2004). Verdeckte Nachrichten über gender/Geschlecht. In Eva Rieger \& Hiltrud Schroeder (eds.), "Diese Frau ist der Rede wert": Festschrift für Luise Pusch, 139-49. Herbolzheim: Centaurus.

Hellinger, Marlis, \& Bussmann, Hadumod (2001). Gender across languages: The linguistic representation of women and men. In Marlis Hellinger \& Hadumod Bussmann (eds.), Gender across languages: The linguistic representation of women and men, 1:1-25. Amsterdam: John Benjamins.

- - (eds.) (2001-2003). Gender across languages: The linguistic representation of women and men. 3 vols. Amsterdam: John Benjamins.

Hornscheidt, Antje (2006). Die sprachliche Benennung von Personen aus konstruktivistischer Sicht: Genderspezifizierung und ihre diskursive Verhandlung im heutigen Schwedisch. Berlin: Mouton de Gruyter.

Johnsen, Ole (2001). He's my sister! Gender inversion in gay men's speech. In Kerstin Nordenstam \& Kerstin Norén (eds.), Språk, kön och kultur: Rapport från Fjärde Nordiska Konferensen om Språk och Kön, Göteborg den 6-7 Oktober 2000, 133-41. Göteborg: Göteborgs Universitet.

Kennison, Shelia M., \& Trofe, Jessie L. (2003). Comprehending pronouns: A role for word-specific gender stereotype information. Journal of Psycholinguistic Research 32:355-78.

Kulick, Don (2003). No. Language \& Communication 23:139-51.

Lakoff, Robin Tolmach (1975). Language and woman's place. New York: Harper \& Row.

Lehrer, Adrienne (1974). Semantic fields and lexical structures. Amsterdam: North-Holland.

Machin, David, \& Thornborrow, Joanna (2003). Branding and discourse: The case of Cosmopolitan. Discourse \& Society 14:453-71.

Men's Health (2003). Men's Health UK Homepage: Media Pack. http://www.menshealth.co.uk/ mediapack/aboutus/index.html [accessed September 1, 2003].

Motschenbacher, Heiko (2006). "Women and men like different things"? - Doing Gender als Strategie der Werbesprache. Marburg: Tectum. 


\section{HEIKO MOTSCHENBACHER}

(2007). Can the term "genderlect" be saved? A postmodernist re-definition. Gender and Language 1:255-78.

(2008a). Werbesprachliche Genderstilisierung für globale Zeitschriften-Communities. In Gudrun Held \& Sylvia Bendel (eds.), Werbung - grenzenlos: Interkultureller Blick auf multimodale Gestaltungsstrategien aktueller Werbetexte, 45-64. Frankfurt am Main: Peter Lang.

(2008b). Structural linguistic gender categories and discursive materialization: A deconstructionist analysis. IULC Working Papers 7:21-46.

(2008c). Speaking commercial femininities and masculinities: Advertising language in Cosmopolitan and Men's Health magazine. In Helen Kelly-Holmes \& Gerlinde Mautner (eds.), Language and the market. Basingstoke, UK: Palgrave Macmillan.

Ochs, Elinor (1992). Indexing gender. In Alessandro Duranti \& Charles Goodwin (eds.), Rethinking context: Language as an interactive phenomenon, 335-58. Cambridge: Cambridge University Press.

Schmid, Hans-Jörg (2003). Do women and men really live in different cultures? Evidence from the BNC. In Andrew Wilson, Paul Rayson \& Tony McEnery (eds.), Corpus linguistics by the lune: A festschrift for Geoffrey Leech, 185-221. Frankfurt am Main: Peter Lang.

Shields, Vickie Rutledge, \& Heinecken, Dawn (2002). Measuring up: How advertising affects selfimage. Philadelphia: University of Pennsylvania Press.

Silveira, Jeanette (1980). Generic masculine words and thinking. In Cheris Kramarae (ed.), The voices and words of women and men, 165-78. Oxford: Pergamon.

Speer, Susan (2005). Gender talk: Feminism, discourse and conversation analysis. London: Routledge.

Stahr, Ingeborg (2000). Frauen - Körper - Identität im Kontext gesellschaftlicher Modernisierung. In Doris Janshen (ed.), Blickwechsel: Der neue Dialog zwischen Frauen- und Männerforschung, 81-105. Frankfurt/Main: Campus.

Striplin, Deborah (2000). The national directory of magazines 2000: Comprehensive presentation of US and Canadian magazines with expanded international coverage. New York: Oxbridge Communications.

Strong, Jeremy (2003). The language of bodybuilding. Paragraph 26(1/2):163-74.

Sveen, Hanna Andersdotter (2005). "Honourable" or "highly-sexed": Adjectival descriptions of male and female characters in Victorian and contemporary children's fiction. Uppsala: Uppsala Universitet.

Tannen, Deborah (1990). You just don't understand: Women and men in conversation. New York: William Morrow.

Wyss, Eva Lia (2002a). Sprache, Subjekt und Identität: Theorie und Praxis sprachlicher Identität am Beispiel von Liebesbriefen aus dem 20. Jahrhundert. In Tamara Faschingbauer (ed.), Neue Ergebnisse der empirischen Genderforschung, 177-206. Hildesheim: Georg Olms.

- (2002b). Körper und Körperlichkeit in Liebesbriefen des 20. Jahrhunderts. ROSA. Zeitschrift für Geschlechterforschung 25:18-20.

(Received 30 July 2007; revision received 7 January 2008; accepted 9 February 2008; final revision received 11 March 2008) 